Background To examine the associations between social characteristics of US states and the presence of laws authorising expedited partner therapy (EPT).

Methods Data were collected from various sources for 2008-2010 on US state healthcare system characteristics (adult enrollment in Medicaid, number of physicians per 100,000), governmental characteristics (the size of state legislatures, percent of state residents in poverty, percent state financial contribution to state STD programme), and state STD morbidity (chlamydia rates per 100,000 among females age 15-24). Data were analysed in an adjusted logistic regression model in SAS.

Results Overall, 23 states have passed legislation authorising EPT as of February 2013. In adjusted analyses, the only healthcare system variable significantly associated with the presence of a state law authorising EPT was higher adult Medicaid enrollment (AOR $=7.871$ [95\% CI: 1.644, 37.685]), which may represent an increased willingness to authorise EPT where publicly-funded healthcare coverage is more widely available. The only other variable significantly associated with the presence of a law authorising EPT was lower chlamydia rates per 100,000 among females age 15-24 (AOR $=0.332$ [95\% CI: 0.122, 0.903]). The presence of a state law authorising EPT did not differ by the size of the state legislature, percent in poverty, percent state contribution to state STD programme, or number of physicians per 100,000.

Conclusions States with higher adult Medicaid enrollment and lower chlamydia rates among females 15-24 were more likely to have a law authorising EPT. Increased adult Medicaid enrollment may represent an increased willingness of a state to provide publicly-funded healthcare services to its residents; the legal acceptability of EPT may thus be associated with general willingness to provide publicly-funded healthcare within a jurisdiction. This may translate to increased social compatibility of laws authorising EPT in non-US jurisdictions characterised by high rates of publiclyfunded healthcare.

\section{P4.120 EVALUATING THE IMPACT OF SHORT TERM FINANCIAL INCENTIVES ON HIV AND STI INCIDENCE AMONG YOUTH IN LESOTHO: A RANDOMISED TRIAL}

doi:10.1136/sextrans-2013-051184.1017

'M Björkman-Nyqvist, ${ }^{2} \mathrm{~L}$ Corno, ${ }^{3} \mathbf{D}$ de Walque, ${ }^{4} \mathrm{~J}$ Svensson. ${ }^{1}$ Stockholm School of Economics, Stockholm, Sweden; 2 University College London, London, UK; ${ }^{3} T$ he World Bank, Washington, DC, United States; ${ }^{4}$ Stockholm University, Institute for International Economic Studies (IIES), Stockholm, Sweden

Background This study tests the hypothesis that a system of rapid feedback and positive reinforcement using a lottery scheme as an incentive to reduce risky sexual behaviour can be used to promote safer sexual activity and reduce HIV incidence among youth in Lesotho.

Methods An unblinded, individually randomised control trial with 3426 participants, males and females 18-30 years old drawn from 30 villages in Lesotho. The intervention linked the receipt of lottery tickets to negative results for rapid tests for curable STIs: syphilis and Trichomonas vaginalis. The study objective was to test the efficacy of the lottery incentive scheme in reducing HIV incidence. Participants were randomly assigned to either a control arm $(n=1347)$ or one of two intervention arms eligible to receive lottery tickets: high $(n=1116)$ or low $(n=963)$ value lottery $(1,000$ or 500 South African Rands). All arms received STI testing, counselling, and STI treatment every four months during two years. All participants were tested for HIV at baseline and after 16, 20 and 24 months. Village level lotteries were organised every 4 months in which STI negative individuals from the intervention arms were eligible to participate and during which 4 lottery winners (2 males, 2 females) were drawn. The primary study outcome is HIV incidence.
Results After 2 years of intervention, HIV incidence was significantly lower among study participants eligible for the lotteries (OR $0.75,95 \%$ CI $0.58-0.97$ ), especially among women (OR $0.67,95 \%$ CI $0.52-0.86)$, and in the group eligible for the high prize lotteries (1000 Rands)(OR 0.69, 95\% CI $0.50-0.98)$. No harm reported.

Conclusion The results indicate that short-term financial incentives to engage in safe sex can lead to a measurable decline in HIV incidence. It would however be advisable to replicate such an intervention in other settings.

\section{P4.121 GOVERNMENT ROLE'S IN SUPPORTING KEY POPULATION NETWORK}

doi:10.1136/sextrans-2013-051184.1018

\section{S Warsono. National AIDS Commission, Jakarta, Indonesia}

In the AIDS response, the involvement of key populations is important. It means that without their contribution in AIDS response, it is impossible to prevent new infection.

To that end, the Indonesian National AIDS Commission supports key population groups to form a national network. With the support of the National AIDS Commission, some network such as Indonesian Drug Users Network, Positive Women Network, LSL Network and Sex Worker Network are formed.

To strengthen the network, the National AIDS Commission provides financial and technical support through Indonesia Partnership Fund since 2009. The financial support was allocated for operational cost and offices. Apart form Indonesia Partnership Fund support, Those networks are also supported Global Fund throuhg National AIDS Commission.

In coordination meetings that conducted every three months with all members of the National AIDS Commission, these networks are also invited as observers and provide important input related to the AIDS response. The coordination meeting led by Minister of Public Welfare in January 2010 have decided that these networks should be a part of the member of the National AIDS Commission. Since then, the network has been facilitated with grants and state funds. The funding provides each network some grants for coordination meeting, leadership training, community mobilisation training and other activities.

With such support, Indonesian government has shown some recognition of the role of networks of key populations in the AIDS response which has enabled the network to collaborate with various government agencies such as with the Ministry of Health and Social Ministry. The support of the other Ministries are also emerging following the recognition of these two Ministries. With a variety of existing support, the network has also been able to strengthen the system within each network to take more active role in the AIDS response.

\section{P4.122 EFFECTIVENESS OF COMMUNIDADES POSITIVAS: A RANDOMISED COMMUNITY-LEVEL COMBINATION HIV PREVENTION INTERVENTION FOR MEN WHO HAVE SEX WITH MEN IN PERU}

doi:10.1136/sextrans-2013-051184.1019

'A Silva-Santisteban, ${ }^{2}$ K A Konda, 'S Leon, ${ }^{1} X$ Salazar, ${ }^{1} C$ Sandoval, ${ }^{2} \mathrm{~J}$ Clark, ${ }^{3} \mathrm{~J} D$ Klausner, ${ }^{3} \mathrm{~T} \mathrm{~J}$ Coates, 'C F Caceres. 'Universidad Peruana Cayetano Heredia, Lima, Peru; '2UCLA Program in Global Health, Lima, Peru; ${ }^{3}$ University of California, Los Angeles, Los Angeles, CA, United States

Introduction Comunidades Positivas was a randomised clinical trial that assessed a community-level structural combination HIV prevention intervention for men who have sex with men (MSM) in Peru from 2008-2011. We used a $2 \times 2$ factorial design to determine the independent and combined effectiveness of community-level behavioural and biomedical HIV/STI prevention interventions. 